\title{
Post-translational Modification Mimicry for Programmable Assembly of Elastin-Based Protein Polymers
}

Dieter M. Scheibel ${ }^{\dagger}$, Md. Shahadat Hossain ${ }^{\dagger}$, Amy L. Smith, Christopher J. Lynch, Davoud Mozhdehi* tThese authors contributed equally to this work.

Department of Chemistry, 1-014 Center for Science and Technology, Syracuse University, Syracuse,

13244, USA

dmozhdeh@syr.edu

\section{Supporting Information}

Table of Contents

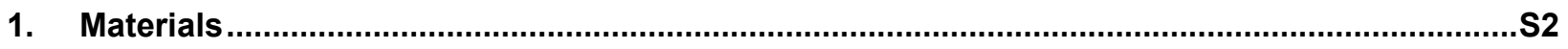

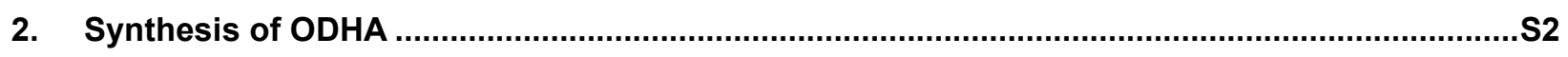

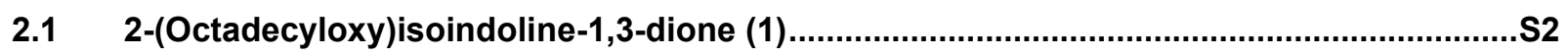

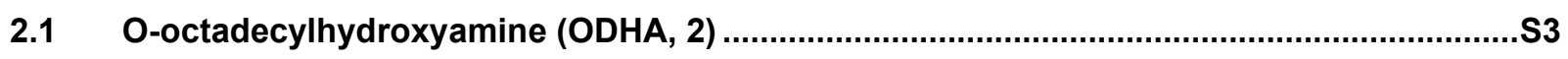

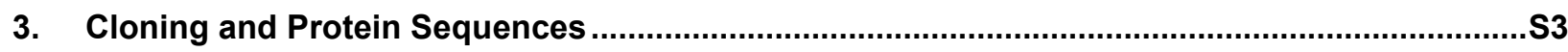

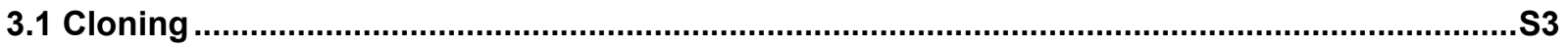

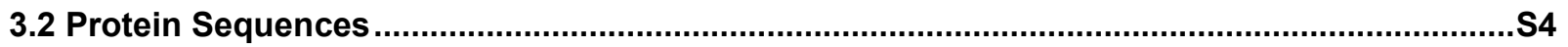

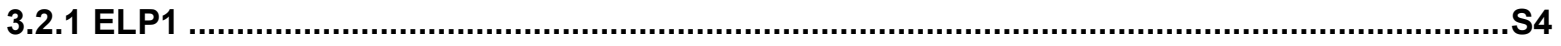

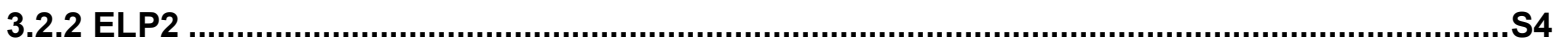

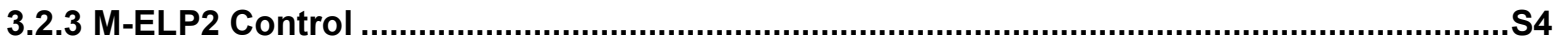

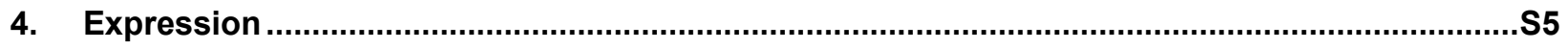

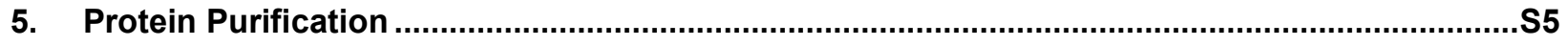

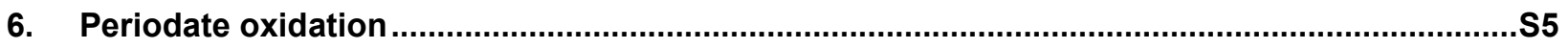

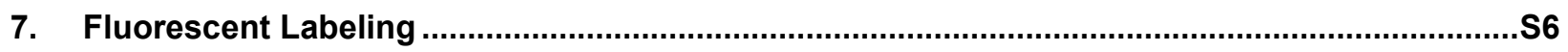

8. Reverse Phase High Performance Liquid Chromatography .................................................... 6

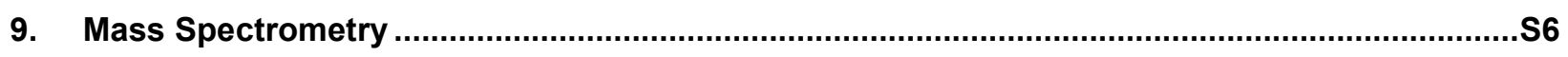

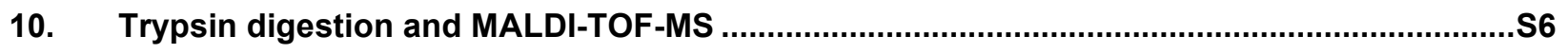

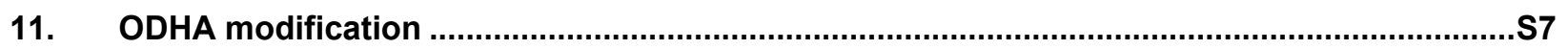

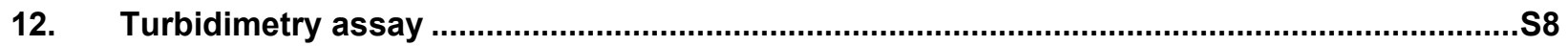

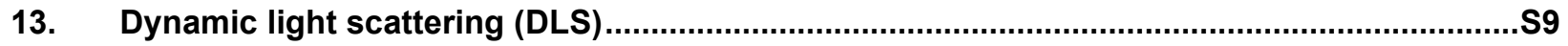

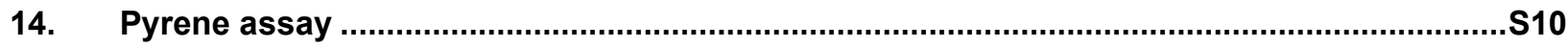

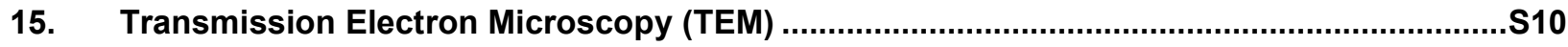

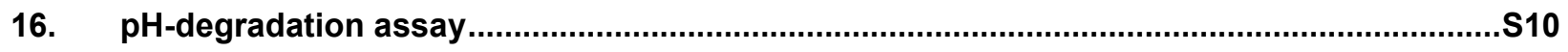

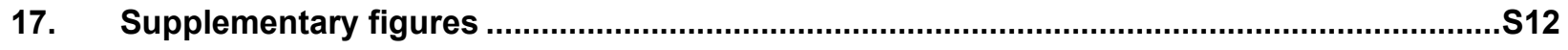

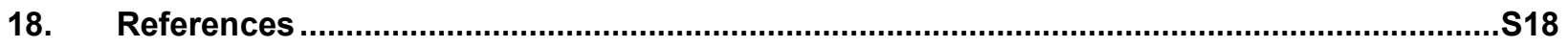




\section{Materials}

The chemically competent Eb5alpha and BL21(DE3) cells, restriction enzymes, ligase, buffers, and DNA extraction and purification kits were purchased from New England Biolabs (Ipswich, MA). Isopropyl $\beta$-D-1-thiogalactopyranoside (IPTG) was purchased from AG Scientific, Inc. (San Diego, CA). Apomyoglobin, adrenocorticotropic hormone (ACTH), sinapinic acid, alpha-cyano-4-hydroxycinnamic acid, trifluoroacetic acid (TFA), N-hydroxyphthalimide, 1-bromooctadecane, triethylamine, polyethyleneimine, $p$-phenylenediamine ( $p$-PDA), pyrene, and hydrazine hydrate were purchased from Sigma-Aldrich Corp. (St. Louis, MO). High-performance liquid chromatography (HPLC)-grade acetonitrile, SnakeSkin ${ }^{\mathrm{TM}}$ dialysis tubing featuring $3.5 \mathrm{~K}$ and $7 \mathrm{~K}$ nominal molecular weight cut off (MWCO), mass spectroscopy grade Pierce ${ }^{\mathrm{TM}}$ trypsin protease, tryptone, yeast extract, sodium chloride, kanamycin, phosphate buffer saline (PBS), ethyl acetate, dimethylformamide, dichloromethane, sodium periodate, Alexa Fluor ${ }^{\mathrm{TM}} 488$ hydrazide, and n-dodecyl- $\beta$-D-maltoside were purchased from Thermo Fisher Scientific (Rockford, IL). Mini-protean ${ }^{\circledR}$ TGX Stain-Free ${ }^{\mathrm{TM}}$ Precast Gels, Precision Plus Protein ${ }^{\mathrm{TM}}$ All Blue Prestained Protein Standard, and Precision Plus Protein ${ }^{\mathrm{TM}}$ Unstained Protein Standards were purchased from Bio-Rad Laboratories, Inc. (Hercules, California). The carbon-coated grid (CF300-Cu) was purchased from Electron Microscopy Sciences (Hatfield, PA). Deionized water was obtained from a Milli-Q® system (Millipore SAS, France). Simply Blue ${ }^{\mathrm{TM}}$ SafeStain was purchased from Novex (Van Allen Way Carlsbad, CA). All chemicals were used as received without further purification.

${ }^{1} \mathrm{H}$ NMR and ${ }^{13} \mathrm{C}$ NMR spectra were recorded using $\mathrm{CDCl}_{3}$ as solvent at $22{ }^{\circ} \mathrm{C}$ on a Bruker AVANCE $400 \mathrm{MHz}$ instrument with the solvent signal as the internal standard. Fourier transform infrared spectroscopy (FT-IR ATR) spectra were obtained on a Bruker Tensor 27 spectrophotometer with an MIR source and a DLaTGS detector. Spectra were recorded under ambient conditions at a resolution of $4 \mathrm{~cm}^{-1}$. A total of 64 scans were recorded for each spectrum and were background corrected.

\section{Synthesis of ODHA}

\section{$2.1 \quad$ 2-(Octadecyloxy)isoindoline-1,3-dione (1)}

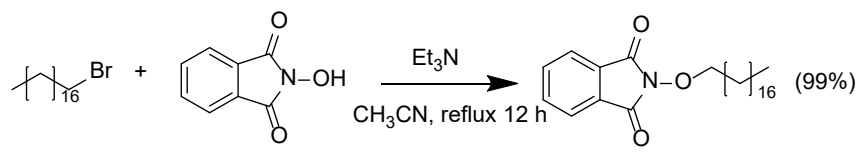

(1)

$\mathrm{N}$-hydroxyphthalimide ( 3.3 grams, $20 \mathrm{mmol}$ ), 1-bromooctadecane (3.3 grams, 10 $\mathrm{mmol})$, triethylamine $(3 \mathrm{~mL}, 40 \mathrm{mmol})$, and acetonitrile $(50 \mathrm{~mL})$ were charged to a $250 \mathrm{~mL}$ round-bottom flask connected to a water-cooled condenser. The solution turned a deep 
red color upon addition of triethylamine indicating formation of the N-hydroxyphthalimide anion. The solution was stirred at reflux for 12 hours. After cooling, solvent was removed via rotary evaporator. The solution was then dissolved in ethyl acetate, washed three times with $50 \mathrm{~mL}$ water and three times with $50 \mathrm{~mL}$ brine, and dried with anhydrous sodium sulfate. Solvent was removed via rotary evaporator to yield a fluffy white solid $\left(R_{f}\right.$ $=0.55,4: 1$ hexane:ethyl acetate). Yield: 4.10 grams $(99 \%)$.

\subsection{O-octadecylhydroxyamine (ODHA, 2)}

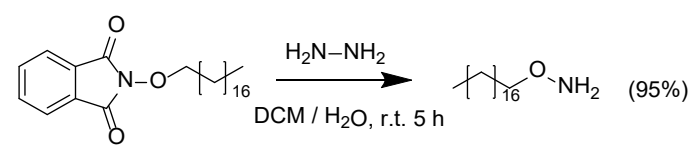

(1)

(2)

2-(Octadecyloxy)isoindoline-1,3-dione (4.1 grams, $9.9 \mathrm{mmol})$ was dissolved in dichloromethane $(50 \mathrm{~mL})$. Hydrazine hydrate $(2 \mathrm{~mL}, 40 \mathrm{mmol})$ was added dropwise to the solution under vigorous stirring. After approximately 10 minutes a fluffy white precipitate formed. Reaction progress was analyzed via TLC (4:1 hexane:ethyl acetate) by monitoring disappearance of the starting material $\left(R_{f}=0.55\right)$, with no starting material observed after 45 minutes. The reaction was stirred for an additional 4 hours and subsequently washed three times with $50 \mathrm{~mL}$ water and one time with $50 \mathrm{~mL}$ brine, dried with anhydrous sodium sulfate. Solvent was removed via rotary evaporator yielding a fluffy white solid. Yield: 2.7 grams (95\%). Characterization data, ${ }^{1} \mathrm{H} N \mathrm{NM},{ }^{13} \mathrm{C}$ NMR, and FT-IR, matched previous literature report (Figure S1-S3). ${ }^{1}$

\section{Cloning and Protein Sequences}

\subsection{Cloning}

A leader sequence, Met-Ser-Lys-Gly-Pro-Gly-Hiss, was fused to the N-terminal of the two ELP sequences using recursive directional ligation by plasmid reconstruction (PReRDL) ${ }^{2}$. This short peptide sequence fulfilled two functions: 1 ) it introduced a single serine residue at the $\mathrm{N}$-terminal of the polypeptide following the cleavage of the translation initiation signal by methionine aminopeptidase; 2 ) it encoded an octa histidine tag that can then be used to purify the model protein using immobilized metal affinity chromatography if necessary. Although we purified proteins using a chromatography-free technique by leveraging their reversible temperature-triggered phase behavior in this study (section 5), we considered the possibility that the introduced aldehyde may not be stable at the elevated temperature required for this procedure. All cloning steps were carried out using NEB5 $\alpha$ E. coli strain. After selection on kanamycin antibiotic plates, positive colonies were identified by Sanger sequencing. 


\subsection{Protein Sequences}

\section{$\underline{3.2 .1 E L P 1}$}

ELP1 contained a mixture of Val and Ala (80:20) at the guest residue position. After every 10 pentapeptide repeat units, a lysine residue was incorporated with a flexible glycine linker, GGK (highlighted in yellow), to increase the hydrophilicity and transition temperature of ELP1. The N-terminal leader sequence is highlighted in green.

(M)SKGPGHHHHHHHHHHGVGVPGVGVPGAGVPGVGVPGVGVPGVGVPGVGVPGAGVPGV GVPGVGVPGGKGVGVPGVGVPGAGVPGVGVPGVGVPGVGVPGVGVPGAGVPGVGVPGVG VPGGKGVGVPGVGVPGAGVPGVGVPGVGVPGVGVPGVGVPGAGVPGVGVPGVGVPGGKG VGVPGVGVPGAGVPGVGVPGVGVPGVGVPGVGVPGAGVPGVGVPGVGVPGGKGVGVPGV GVPGAGVPGVGVPGVGVPGVGVPGVGVPGAGVPGVGVPGVGVPGGKGVGVPGVGVPGAG VPGVGVPGVGVPGVGVPGVGVPGAGVPGVGVPGVGVPGGKGVGVPGVGVPGAGVPGVGV PGVGVPGVGVPGVGVPGAGVPGVGVPGVGVPGGKGVGVPGVGVPGAGVPGVGVPGVGVP GVGVPGVGVPGAGVPGVGVPGVGVPGGKGY

\section{$\underline{3.2 .2 E L P 2}$}

ELP2 contained Val only at the guest residue position with 40-pentapeptide repeat units. The $\mathrm{N}$-terminal leader sequence is highlighted in green.

(M)SKGPGHHHHHHHHHHGVGVPGVGVPGVGVPGVGVPGVGVPGVGVPGVGVPGVGVPGV GVPGVGVPGVGVPGVGVPGVGVPGVGVPGVGVPGVGVPGVGVPGVGVPGVGVPGVGVPG VGVPGVGVPGVGVPGVGVPGVGVPGVGVPGVGVPGVGVPGVGVPGVGVPGVGVPGVGVP GVGVPGVGVPGVGVPGVGVPGVGVPGVGVPGVGVPGVGVPGY

\subsubsection{M-ELP2 Control}

The following myristoylated ELP2 was used as a non-pH responsive control. The $\mathrm{N}$ terminal leader sequence highlighted in green is composed of two segments: 1) a recognition sequence for $\mathrm{N}$-myristoyl transferase enzyme (NMT) derived from yeast ADP ribosylation factor 2 (underlined); 2) An Octa histidine tag which can be used for purification of protein using metal affinity chromatography. M-ELP2 can be produced by co-expression of this protein with NMT enzyme in E.coli. The enzyme will transfer a myristoyl group to the first glycine residue (shown with bold typeface) of ELP2. The initial formyl methionine (italicized) will be removed by methionine aminopeptidase during recombinant expression.

(M)GLYASKLFSNLGHHHHHHHHHHGVGVPGVGVPGVGVPGVGVPGVGVPGVGVPGVGVPG VGVPGVGVPGVGVPGVGVPGVGVPGVGVPGVGVPGVGVPGVGVPGVGVPGVGVPGVGVP GVGVPGVGVPGVGVPGVGVPGVGVPGVGVPGVGVPGVGVPGVGVPGVGVPGVGVPGVGV PGVGVPGVGVPGVGVPGVGVPGVGVPGVGVPGVGVPGVGVPGVGVPGY 
The details of co-expression and purification of myristoylated construct is reported in our previous publications. ${ }^{3-5}$

\section{Expression}

A $50 \mathrm{~mL}$ of sterile $2 \mathrm{X}$ YT medium with kanamycin was inoculated with a single bacterial colony. The culture was then incubated at $37^{\circ} \mathrm{C}$ while shaking at $200 \mathrm{rpm}$. After overnight growth, cells were harvested by centrifugation $\left(3745 \mathrm{~g}, 15 \mathrm{~min}, 4{ }^{\circ} \mathrm{C}\right)$ and resuspended in $6 \mathrm{~mL}$ of PBS. Then $1 \mathrm{~mL}$ of this suspension was used to inoculate each one liter of sterile $2 \mathrm{X}$ YT medium. Bacteria were grown in an orbital shaker incubator at $37^{\circ} \mathrm{C}$ at $180 \mathrm{rpm}$. After reaching an $\mathrm{OD}_{600}$ value of 0.8 , the expression was induced by the addition of IPTG to a final concentration of $1 \mathrm{mM}$. The expression of proteins was then continued for $16 \mathrm{~h}$. Cells were harvested by centrifugation $\left(3745 \mathrm{~g}, 30 \mathrm{~min}, 4^{\circ} \mathrm{C}\right)$ and resuspended in PBS (6 $\mathrm{mL}$ per $1 \mathrm{~L}$ of expression culture).

\section{Protein Purification}

Proteins were purified by inverse transition cycling (ITC). ${ }^{6}$ After cell lysis using sonication (10 s on, $50 \mathrm{~s}$ off, a total sonication time of $90 \mathrm{~s}$; power $60-80 \mathrm{~W}$ ), $10 \% \mathrm{w} / \mathrm{v}$ polyethylenimine ( $2 \mathrm{~mL}$ per $\mathrm{L}$ of expression culture) was added to the bacterial solution to remove nucleic acid fragments. The solution was then centrifuged $\left(22,830 \mathrm{~g}, 4{ }^{\circ} \mathrm{C}, 15\right.$ $\mathrm{min}$ ) to separate protein from insoluble cell debris. The supernatant was subjected to two rounds of bakeouts by heating at $65^{\circ} \mathrm{C}$ for 10 minutes, followed by cooling on ice for 20 minutes and finally, centrifugation $\left(22,830 \mathrm{~g}, 4^{\circ} \mathrm{C}, 15 \mathrm{~min}\right)$. ELPs were then purified by two rounds of ITC on the bakeout supernatant. In each round, the phase-transition of the proteins were triggered isothermally by the addition of $\mathrm{NaCl}$. The protein coacervate was then obtained with "hot spin" centrifugation $\left(22,830 \mathrm{~g}, 40{ }^{\circ} \mathrm{C}, 15 \mathrm{~min}\right)$. The protein pellet was resuspended in PBS and centrifuged $\left(22,830 \mathrm{~g}, 4{ }^{\circ} \mathrm{C}, 15 \mathrm{~min}\right)$ for a "cold spin" step.

\section{Periodate oxidation}

ELPs $(200 \mu \mathrm{M}$ in PBS) was mixed with $5 \mathrm{X}$ excess sodium periodate $(1.04 \mathrm{mM})$ at room temperature for 15-20 minutes in phosphate buffer $(\mathrm{pH} 8)$. The periodate reaction was quenched using two rounds of ITC. $\mathrm{NaCl}$ was added $(\sim 200-300 \mu \mathrm{mol}$ as $\mathrm{NaCl}$ solution) to each periodate reaction and heated to $40{ }^{\circ} \mathrm{C}$, then cleared through centrifugation at $40{ }^{\circ} \mathrm{C}$. The pellet was then resuspended in cold phosphate buffer $\mathrm{pH} 8$ and centrifuged at $4{ }^{\circ} \mathrm{C}$. A hot spin was repeated by initiating ELP transition with $0.5 \mathrm{M}$ $\mathrm{NaCl}$, heated at $40^{\circ} \mathrm{C}$, and cleared by centrifugation. The pellet was then resuspended in the reaction buffer. 


\section{Fluorescent Labeling}

A $50 \mu \mathrm{L}$ reaction containing $1 \mu \mathrm{L}$ of protein cold spin 2 supernatant or periodate oxidation cold spin 2 supernatant, $140 \mu \mathrm{M}$ of AF488-NHNH 2 in sodium acetate buffer $(\mathrm{pH}$ 5), was allowed to rotate at $37^{\circ} \mathrm{C}$ for $16-18$ hours. After the incubation period, SDS Page was used to analyze the reaction $(5 \mu \mathrm{L}$ of the fluorophore reaction, $5 \mu \mathrm{L} 4 \mathrm{X}$ Laemmli buffer, $10 \mu \mathrm{L}$ ultrapure water), $10 \mu \mathrm{L}$ was added onto a $10 \%$ TGX stain-free gel. The protein gel was exposed to $300 \mathrm{~V}$ for 25 minutes. The gel image was visualized using 470 $\mathrm{nm}$ light, $350 \mathrm{~nm}$ light, and Coomassie blue staining.

\section{Reverse Phase High Performance Liquid Chromatography}

Analytical RP-HPLC was performed on a Shimadzu instrument using a Phenomenex Jupiter 8 m C4 $300 \AA, 250 \times 4.6 \mathrm{~mm}$ LC Column with a mobile phase consisting of solvent $\mathrm{A}$ : $\mathrm{H}_{2} \mathrm{O}+0.1 \%$ TFA, solvent $\mathrm{B}$ : acetonitrile $+0.1 \%$ TFA, Table $\mathrm{S} 1$. Proteins were analyzed using a photodiode array detector at wavelengths between 190 and $800 \mathrm{~nm}$.

Table S1: The gradient mobile phase composition of analytical HPLC.

\begin{tabular}{cc}
\hline Time $(\min )$ & $\begin{array}{c}\% \mathrm{~B}\left(\mathrm{CH}_{3} \mathrm{CN}+\right. \\
0.1 \% \text { TFA })\end{array}$ \\
\hline 0 & 0 \\
5 & 0 \\
45 & 90 \\
\hline
\end{tabular}

\section{Mass Spectrometry}

Matrix-assisted laser desorption/ionization time-of-flight mass spectrometry (MALDI-TOF-MS) was conducted on a Bruker Autoflex III with a smart ion source. Samples for MALDI-TOF-MS analysis were prepared by mixing protein solutions with sinapinic acid as the MALDI matrix. These solutions were plated onto a sample plate and dried at room temperature. Apomyoglobin was used as a standard to calibrate the instrument.

Liquid chromatography-mass spectrometry (LC-MS) was conducted on Shimadzu LCMS-8040.

\section{Trypsin digestion and MALDI-TOF-MS}

We conducted trypsin digestion according to the manufacturer's protocol (Pierce trypsin, Thermo Scientific). Briefly, the protein was incubated with trypsin in a $50 \mathrm{mM}$ 
ammonium bicarbonate buffer $(\mathrm{pH}=7.8)$ for $2 \mathrm{~h}$. The peptide fragments were analyzed by MALDI-TOF-MS using a-cyano-4-hydroxycinnamic acid as the matrix. Adrenocorticotropic hormone was used as a standard for the calibration of trypsindigested peptide fragments.

\section{ODHA modification}

A stock solution of ODHA was prepared in DMF. After oxidation of protein and removal of excess oxidizing agent (section 6$)$, the protein solution ( $0.36 \mathrm{mM}$ in PBS) was mixed with ODHA (final concentration $1.5 \mathrm{mM}, 5$ equiv) and the reaction mixture was supplemented with $10 \mathrm{mM}$ para-phenylenediamine ( $p-P D A)$ as a nucleophilic catalyst. The reaction mixture was mixed on an end-to-end rotator at $37^{\circ} \mathrm{C}$ for $12 \mathrm{~h}$. Afterwards, the organic solvent was removed in vacuo or by dialysis against water. The unreacted ODHA, which is no longer soluble in water, was removed by filtration or centrifugation. The crude reaction mixture was first analyzed by RP-HPLC as the lipidated product had a longer retention time compared to unmodified protein $\left(\Delta t_{R}=1 \mathrm{~min}\right)$.

Since modification with ODHA lowered the LCST transition temperature of the protein, it is possible to purify the modified protein from the reaction mixture by leveraging its phase behavior using ITC. Briefly, the phase behavior of the modified ELP was triggered isothermally by addition of sodium chloride from a concentrated aqueous stock solution $(5 \mathrm{M})$. The protein coacervates were then collected using centrifugation and resuspended in PBS before being subjected to another round of ITC. The progress of purification was monitored using RP-HPLC after each round. For self-assembly studies, we further purified each construct using RP-HPLC to achieve $>95 \%$ purity. Since the HPLC eluents contain $0.1 \%$ TFA, the collected peaks were immediately neutralized by addition of PBS before dialysis against water to remove the organic solvents. All HPLCpurified proteins were then lyophilized and kept at $-20{ }^{\circ} \mathrm{C}$ for long-term storage.

We also conducted the lipidation reaction in the presence of mild non-ionic surfactants, Triton X-100 (2 mM) or dodecyl- $\beta$-D-maltoside $(1 \% \mathrm{w} / \mathrm{v})$, which increase the solubility of the ODHA in the aqueous environment. This method is advantageous if the desired protein is unstable (i.e., denatures) in the presence of organic solvents. The reaction condition (concentration of reagents, time, temperature, and purification) were same as discussed above.

We have used a variation of the equation used by Wendeler et al. to calculate the reaction rate based on the conversion data. ${ }^{7}$ Briefly, we assumed that the reaction between the oxidized protein and the lipid is a bimolecular reaction following secondorder rate kinetics. Under the lipidation reaction condition, we have also assumed that the rate of the forward reaction is much faster than the rate of the reverse reaction (hydrolysis), as the lipidation reaction $\mathrm{pH}$ is $\sim 5.5$. Under this condition, the rate of the 
formation of ODHA-modified protein is related to the concertation of reactants, oxidized protein (ELP) and the lipid (ODHA):

$$
\frac{d[O D H A-E L P]}{d t}=k[E L P][O D H A]
$$

This equation can be integrated to relate the concentration of ODHA-ELP to time and the initial concentration of ELP and ODHA, [ELP]o and [ODHA]o. Since ODHA was used as an excess reagent, its initial concentration can be expressed as [ODHA] $=m \times$ [ELP]o; $m>1$.

$$
[O D H A-E L P]=\frac{[E L P]_{0}\left(e^{(m-1)[E L P]_{0} k t}-1\right)}{e^{(m-1)[E L P]_{0} k t}-0.19}
$$

We have determined the rate constant by fitting the experimentally determined values of [ODHA-ELP] as a function of reaction time to equation (2) using nonlinear regression (conducted automatically using GraphPad prism software). Under these reaction conditions, the experimentally determined rate constant for the formation of ODHA-ELP2 is $5.6 \times 10^{-3} \mathrm{M}^{-1} \mathrm{~s}^{-1}, 90 \%$ confidence interval $=2.1-10.9 \times 10^{-3} \mathrm{M}^{-1} \mathrm{~s}^{-1}(\mathrm{~N}=5)$. Similar kinetics was observed for the reaction of ELP1 with ODHA, $12 \times 10^{-3} \mathrm{M}^{-1} \mathrm{~s}^{-1}(\mathrm{~N}=$ 2). The observed reaction rate is consistent with the prototypical oxime formation at this $\mathrm{pH} .{ }^{1}$

We are cognizant that this model does not consider the possible micellization of ODHA in water or its incorporation into detergent micelles, which results in a reduction of the ODHA concentration in the solution. Therefore, the actual rate of reaction is likely to be faster than the observed rate.

\section{Turbidimetry assay}

We performed the turbidimetry assay on an Agilent UV-vis spectrophotometer (Cary 300) with a Peltier temperature control system. Protein solutions in PBS were taken into a cuvette, and the turbidity of the solution was quantified by measuring absorbance at $350 \mathrm{~nm}$ while heating the protein solution from 20 to $40{ }^{\circ} \mathrm{C}$ for lipidated proteins (20 to $60{ }^{\circ} \mathrm{C}$ for nonlipidated constructs) at a rate of $1^{\circ} \mathrm{C} / \mathrm{min}$.

The LCST phase transition of ELP is primarily driven by the changes in the entropy of the system (ELP chains and solvent molecules) as the temperature is increased above the could point. A simplified empirical model (that is based on Flory-Huggins theory of polymer phase separation) describes the relationship between the observed transition temperature and the concentration of ELP chain in solution: $\left.T_{t}=T_{c}+m \ln ([E L P])\right)^{8,9}$ Addition of ODHA yields to a reduction in $\mathrm{T}_{c}$, manifested in the reduction of observed transition temperatures for lipidated constructs.

We suggest that the reduction of transition temperature is driven by the increase in the magnitude of the entropy difference of the solvent molecules between one-phase and two-phase states. Below the transition temperature, some water molecules are bound to the ELP chain or trapped in segments of the hydrophobic core. Increasing the 
temperature above LCST results in the release of these water molecules and thus increasing the magnitude of $\Delta S$ between two states, and reduction in the temperature of phase transition (assuming a temperature-independent enthalpic contribution: $\Delta G=0$ at phase transition and $T_{t}=\Delta \mathrm{H} / \Delta S$ ). In other words, the more hydrophobic ODHA-ELP requires a lower temperature to phase separate from the water compared to unmodified ELP.

On the other hand, the concentration dependence of transition temperature is primarily driven by the changes in the entropy of the ELP chains between two states (homogenous 1-phase vs. 2-phase coacervates), $\Delta S \sim R \ln [E L P]^{\text {solution, assuming that }}$ contribution to entropy from ELPs in the coacervates is negligible as coacervates are highly concentrated (less degree of freedom for polymer chain). ${ }^{10}$ We suggest that once ODHA-ELP chains self-assemble, the local concentration of the ELP in each micelle increases and becomes independent of the bulk concentration. ${ }^{11,12}$ In other words, the magnitude of entropy changes between two states varies less with the changes in the concentration of ELP in bulk solution as the micelles assemble in a similar fashion across a wide range of concentrations if $[E L P]>$ critical micelle concentration.

\section{Dynamic light scattering (DLS)}

Dynamic light scattering was conducted on a Zetasizer nano ZS (Malvern Instruments) with a $173^{\circ}$ backscattering detector. The protein samples for DLS were freshly prepared in PBS. After centrifugation $\left(21000 \mathrm{~g}, 5 \mathrm{~min}, 4^{\circ} \mathrm{C}\right)$, the supernatant was taken into a DLS cuvette and analyzed at $15^{\circ} \mathrm{C}(\mathrm{T}<\mathrm{LCST})$. The protein sample was incubated at $15^{\circ} \mathrm{C}$ for $1 \mathrm{~min}$ before the start of the measurement.

Multi-angle dynamic light scattering (MADLS) was conducted using Zetasizer Ultra (Malvern Instruments) at three scattering angles $\left(13^{\circ}, 90^{\circ}\right.$, and $\left.173^{\circ}\right)$ at $15^{\circ} \mathrm{C}$. The scattering correlation functions were analyzed by ZS Xplorer software using the generalpurpose analysis model in the program to determine the intensity-distribution profiles. Dispersity in particle sizes and shapes (morphology) results in different scattering profiles at each angle.

As shown Figure S6a, we observed very similar sizes (peak average and distribution) for each collection angle. Based on this data, we propose that the ODHA-modified ELPS self-assemble into monodisperse spherical particles. Spherical particles exhibit similar scattering cross-sections (circles) when viewed across different angles. However, we point out that we also observed a small percentage of larger aggregates, especially at $13^{\circ}$ (as the larger particles scatter strongly at lower angles). Given these results, we suggest that the Zavg obtained from cumulants analysis (which provides a holistic picture of the particle sizes) is likely to overestimate the hydrodynamic radius of the particles as the small population of larger particles skew the results. We, therefore, used the numberdistribution for the analysis of ODHA-ELP samples. As shown in Figure S6b, the numberintensity distribution at standard $173^{\circ}$ angle shows that ODHA-ELP forms particles with 
an average diameter of $23.5 \pm 0.5 \mathrm{~nm}(\mathrm{~N}=3)$, which is in general agreement with sizes obtained from TEM.

\section{Pyrene assay}

Pyrene assays were conducted following a previously developed protocol at $20{ }^{\circ} \mathrm{C} .{ }^{5}$ Pyrene fluorescence was measured using a Cary Eclipse Fluorescence Spectrophotometer at an excitation wavelength of $334 \mathrm{~nm}$. The emission signal was recorded between $350-450 \mathrm{~nm}$ at $1 \mathrm{~nm}$ intervals with the scan rate of $600 \mathrm{~nm} / \mathrm{min}$.

\section{Transmission Electron Microscopy (TEM)}

The TEM imaging was performed on a JEOL-2100F, operated at $200 \mathrm{kV}$; images were recorded by a Gatan charge-coupled device (CCD) camera. Samples of ODHA-ELP in water were deposited onto a carbon-coated grid (CF300-Cu, Electron Microscopy Sciences) for $5 \mathrm{~min}$. Excess solution was blotted, and the grid was then stained with 10 $\mu \mathrm{L}$ of $1 \%$ uranyl acetate for 1 minute. After blotting excess stain, the grid was washed four times with ultrapure water. The grid was dried at room temperature for $2 \mathrm{~h}$, followed by vacuum drying for $12 \mathrm{~h}$.

\section{6. $\mathrm{pH}$-degradation assay}

$\mathrm{pH}$ degradation assays were conducted by dissolving the protein sample $(33 \mu \mathrm{M})$ in citric acid buffer $(100 \mu \mathrm{M}, \mathrm{pH}=1,2$, or 3 , supplemented with $40 \%$ acetonitrile) in an $\mathrm{HPLC}$ vial. The reaction mixture was stirred at $37{ }^{\circ} \mathrm{C}$ and $50 \mu \mathrm{L}$ aliquots were taken at predetermined time intervals and analyzed by RP-HPLC. The area under the curve was used to quantify the concentration of lipidated (starting material) and nonlipidated proteins (product).

We used dynamic light scattering to confirm that the observed hydrolysis of the ODHA-ELP2 results in the disassembly of the protein nanoparticles (Figure S12). For this experiment, protein samples ( $\mathrm{pH}$-responsive ODHA-ELP2 and non $\mathrm{pH}$-responsive $\mathrm{M}$ ELP2) were incubated in citrate buffer without acetonitrile $(\mathrm{pH}=1)$ at $37^{\circ} \mathrm{C}$. At the designated time points, $50 \mu \mathrm{L}$ of each sample was collected from the degradation mixture and cooled down to $15^{\circ} \mathrm{C}$ before DLS analysis. The scattering intensities were analyzed using cumulants methods (which is commonly used for the analysis of polydisperse samples, i.e., a mixture of micelles and unimers). ${ }^{13}$ As shown in Figure S12, under acidic conditions, ODHA-ELP2 nanoparticles were disassembled as the $Z_{\text {avg }}$ was reduced from $49.1 \pm 4.5 \mathrm{~nm}$ to $9.3 \pm 1 \mathrm{~nm}$. The average size of myristoylated control (M-ELP2) remained constant even when the sample was incubated for up to 28 hours. Each time point sample was also analyzed by RP-HPLC to ensure a similar degradation (ODHA-ELP2) or stability profile (M-ELP2) is observed at conditions used in this study (data not shown).

The intrinsic stability of the oxime (and hydrazone) conjugates is influenced by the electronic contributions of functional groups in the vicinity of this linkage. ${ }^{14}$ 
Mechanistically, oxime hydrolysis proceeds by protonation of the nitrogen group, followed by the nucleophilic addition of water to the activated imine group to form a carbinolamine intermediate. Even though the first step is usually not rate-limiting step, previous experimental and computational studies have demonstrated that the proton affinity of the nitrogen is a predictive indicator of the oxime stability. ${ }^{15,16}$ For $\alpha$-glyoxylyl group, the electron-withdrawing nature of the neighboring carbonyl group increases the acidity of the nitrogen, thus lowering the proton affinity (and hydrolysis rate) of this oxime linkage. ${ }^{17,18}$

Similarly, the equilibrium constant for the formation of oximes (reverse reaction of hydrolysis) is influenced by the nature of the aldehyde or ketone group. For example, the equilibrium constant of the oxime prepared from pyruvic acid is $2000 \times$ larger than analogous oxime prepared from acetone. ${ }^{18}$

The increased hydrolytic stability of ODHA-ELP is advantageous for certain applications including oral drug delivery and release in response to low gastric $\mathrm{pH}$. However, for programmable disassembly in higher pHs (e.g., $\mathrm{pH}=4.5$ in endosomes), we suggest the mutation of the oxime linkage to hydrazone or semicarbazones, which are known to be more labile in lower $\mathrm{pH}$. Alternatively, using a different bio-orthogonal approach, it is possible to change the position of the aldehyde group from $\mathrm{N}$-terminal to a side chain to form conjugates with a faster disassembly rate. 


\section{Supplementary figures}

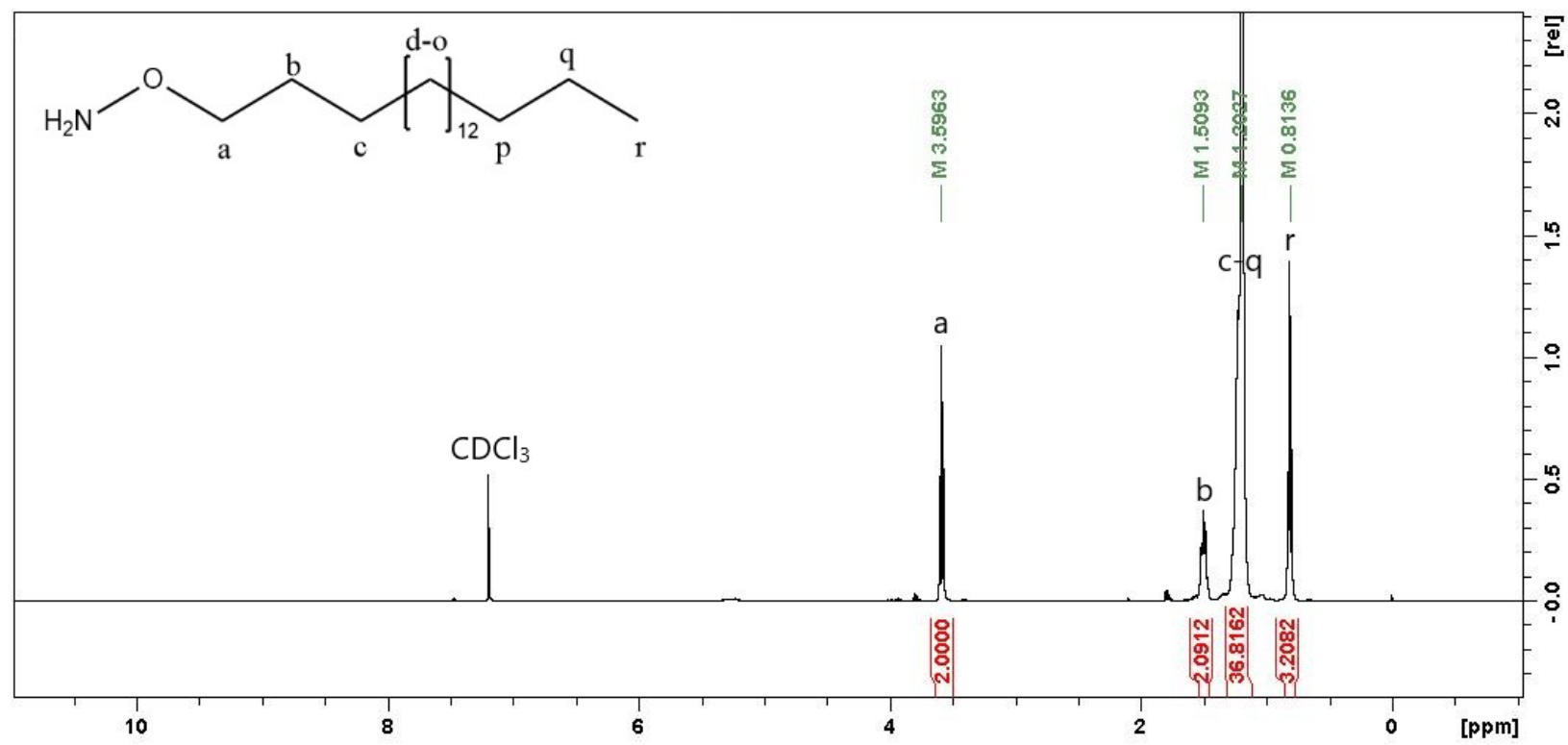

Figure S1. ${ }^{1} \mathrm{H}$ NMR spectra of ODHA in $\mathrm{CDCl}_{3}$.

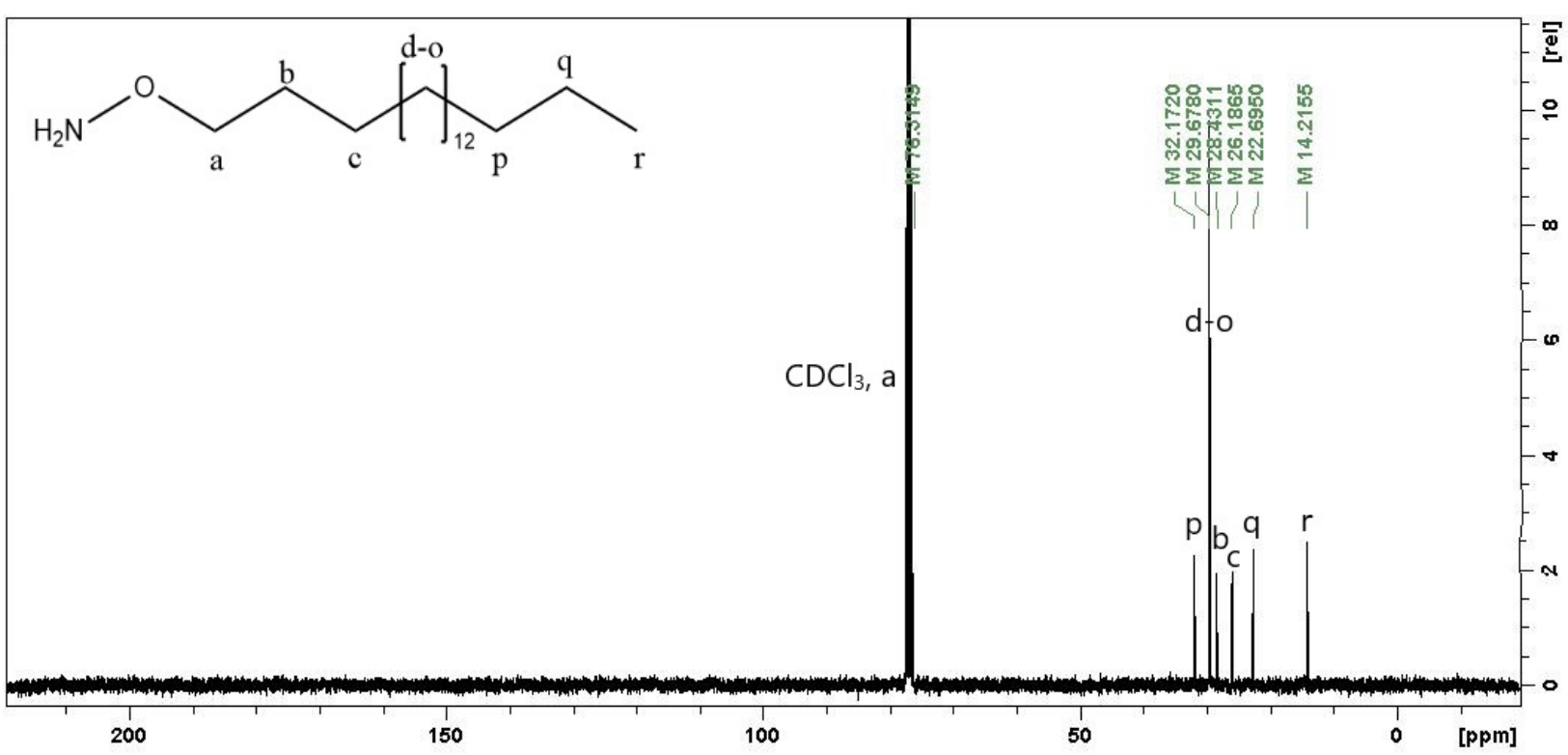

Figure S2. ${ }^{13} \mathrm{C}$ NMR of ODHA in $\mathrm{CDCl}_{3}$. 


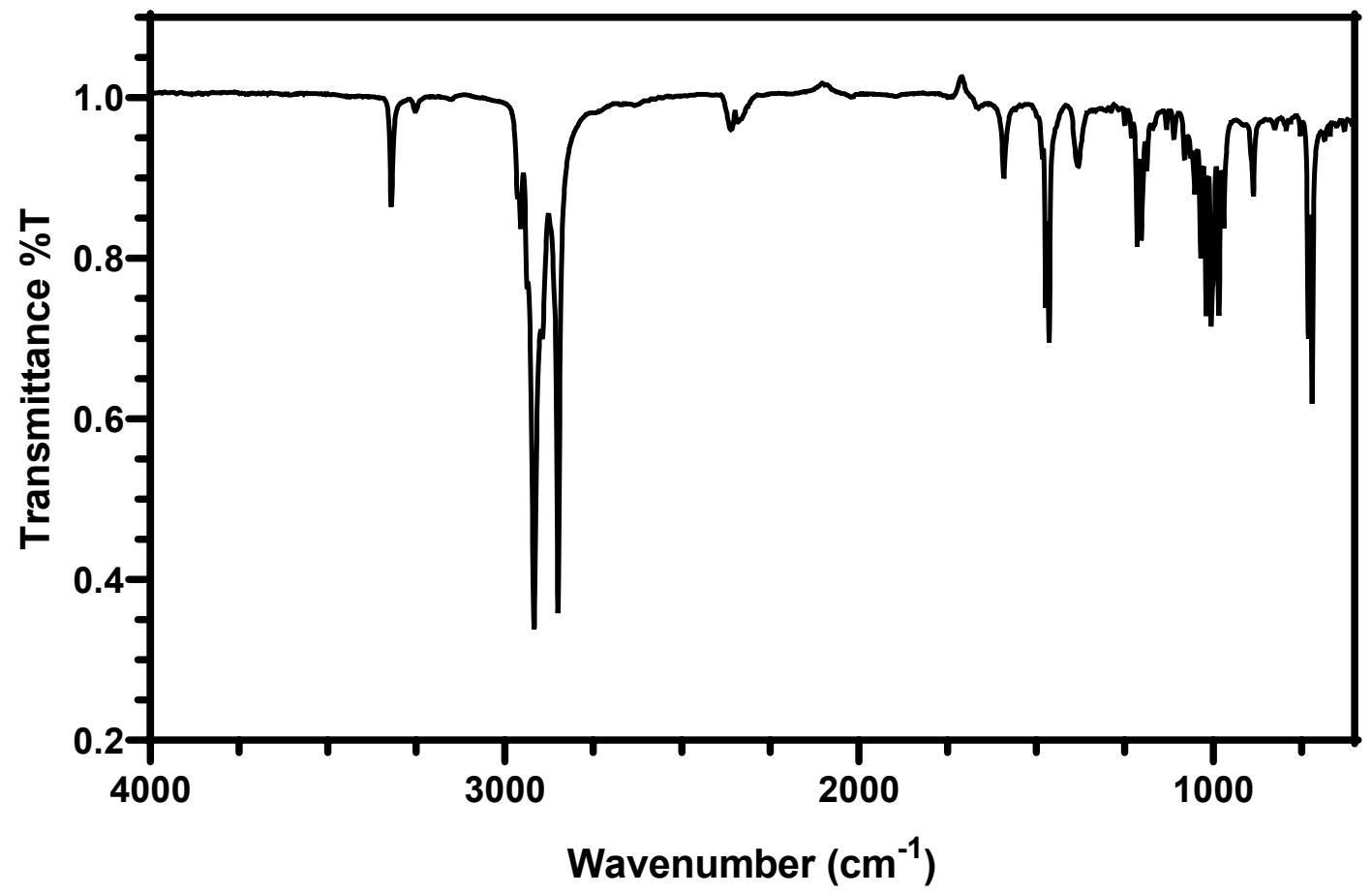

Figure S3. Attenuated Total Reflection Fourier Transform Infrared Spectroscopy (ATR-FT-IR) spectra of ODHA.

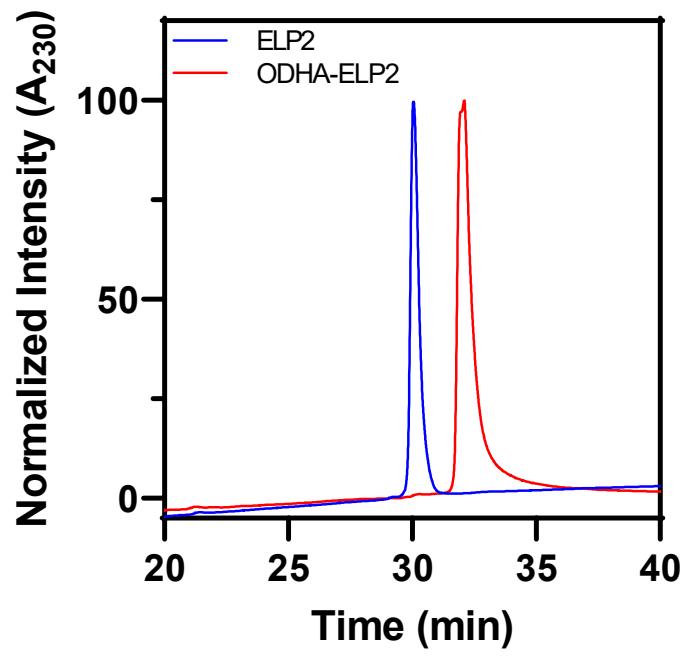

Figure S4. Analytical RP-HPLC chromatogram of ODHA-ELP2 (red curve) and unmodified ELP2 (blue curve). RP-HPLC confirms the purity of each construct. The increased retention time of ODHA-ELP2 is consistent with the increased hydrophobicity of this construct. 


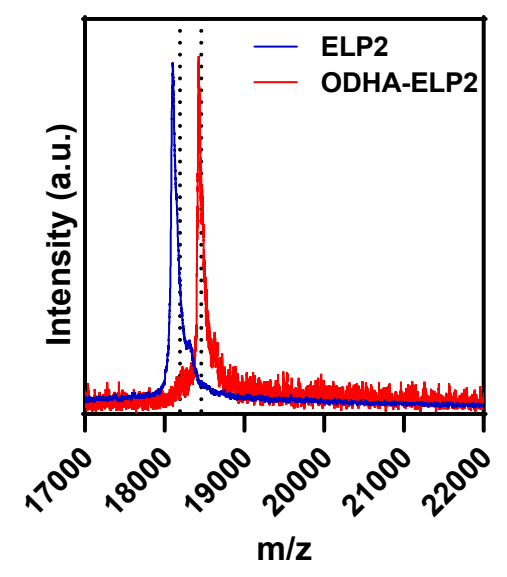

Figure S5. MALDI-TOF-MS spectra of ELP2 (blue curve) and ODHA-ELP2 (red curve). The dotted vertical lines represent the theoretical molecular weight of each construct.
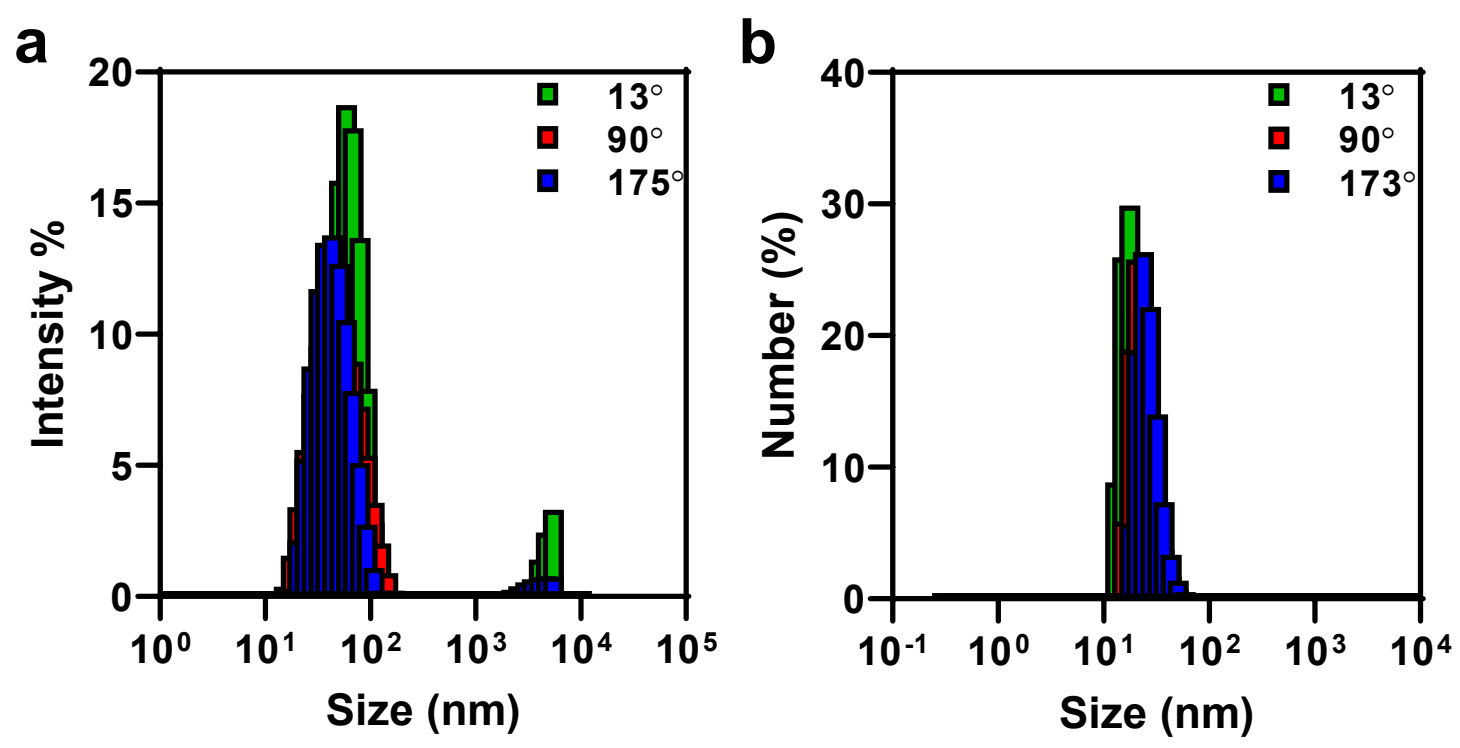

Figure S6. Multi-angle dynamic light scattering and number-distributions for ODHA-modified constructs. a) Representative scattering intensity-distributions for ODHA-ELP2 at $13^{\circ}, 90^{\circ}$, and $175^{\circ}$. b) The numberdistribution for ODHA-ELP2 at each angle. 


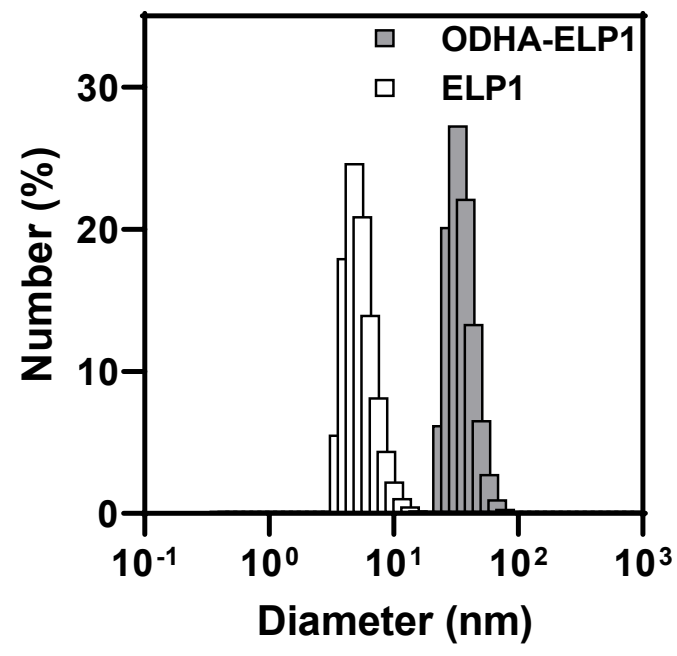

Figure S7. Dynamic light scattering analysis of the self-assembly of ELP1 (dark grey) and ODHA-ELP1 (light grey). Number-distributions are derived by the analysis of scattering data. Samples were prepared by dissolving lyophilized protein in PBS. Measurements were conducted at $25^{\circ} \mathrm{C}(\mathrm{T}<\mathrm{LCST})$.
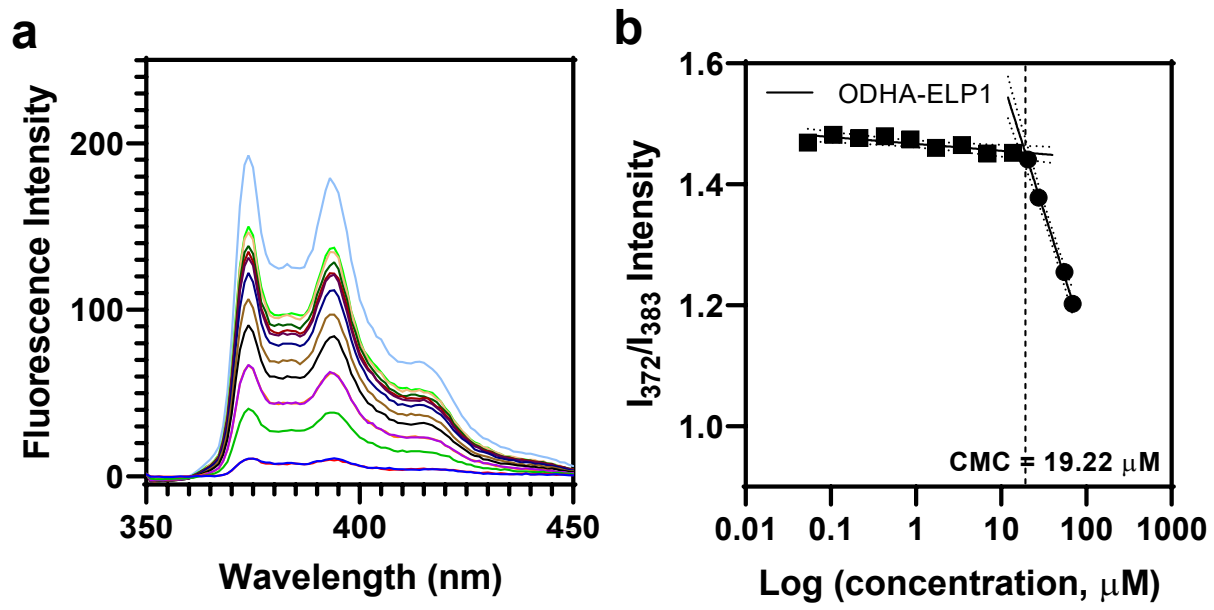

Figure S8. Pyrene fluorescence assay to determine the critical micelle concentration (CMC) of ODHAELP1. a) Raw fluorescence data from pyrene assay. b) Calculated peak 1 to peak 3 absorbance ratios for pyrene fluorescence are plotted against the concentration of ODHA-ELP1, made in serial dilutions. The calculated CMC is shown as a dashed vertical line. 


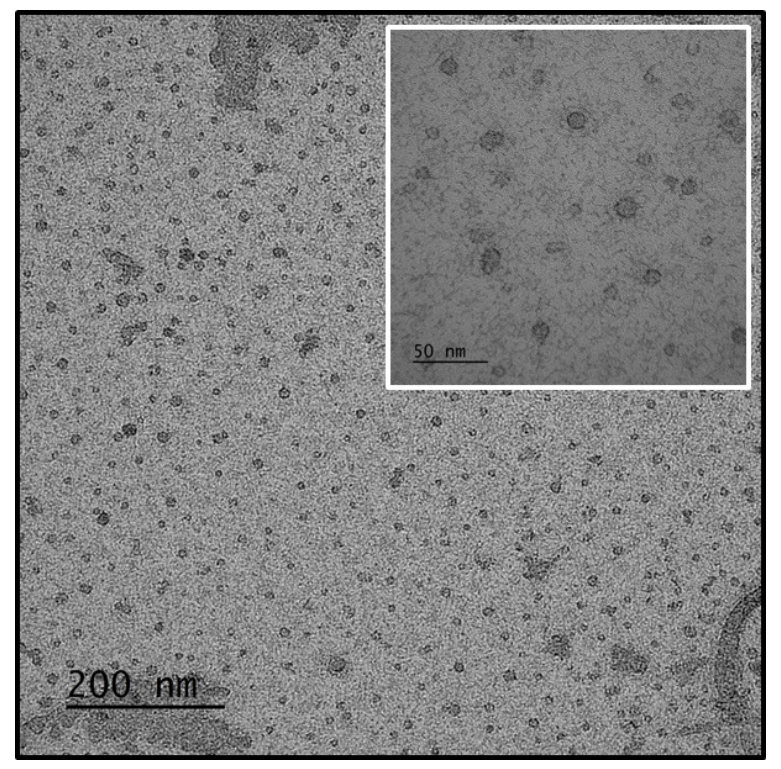

Figure S9. TEM of negatively stained ODHA-ELP1, which forms spherical micelles with an average diameter of $13.7 \pm 2.5 \mathrm{~nm}$.
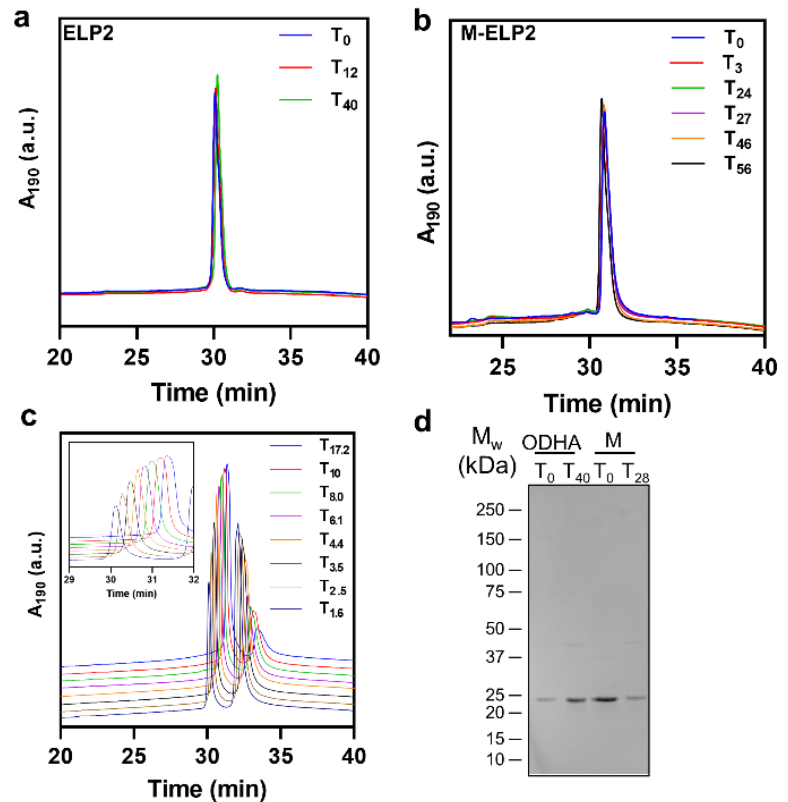

d

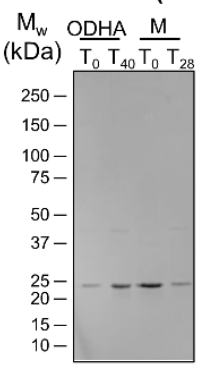

Figure S10. Characterization of acid-mediated degradation of ELP2, M-ELP2, and ODHA-ELP2 in acidic buffer (citrate, $\mathrm{pH}=1$ ). ELP2 (a) and M-ELP2 (b) proteins do not degrade after prolonged incubation in an acidic environment. c) ODHA-ELP2 rapidly degrades into ELP2, and no side product of degradation is observed. d)SDS-PAGE analysis does not show any evidence of species with lower molecular weight (or ladder-like bands), which are expected from a non-specific acid degradation of the backbone. 


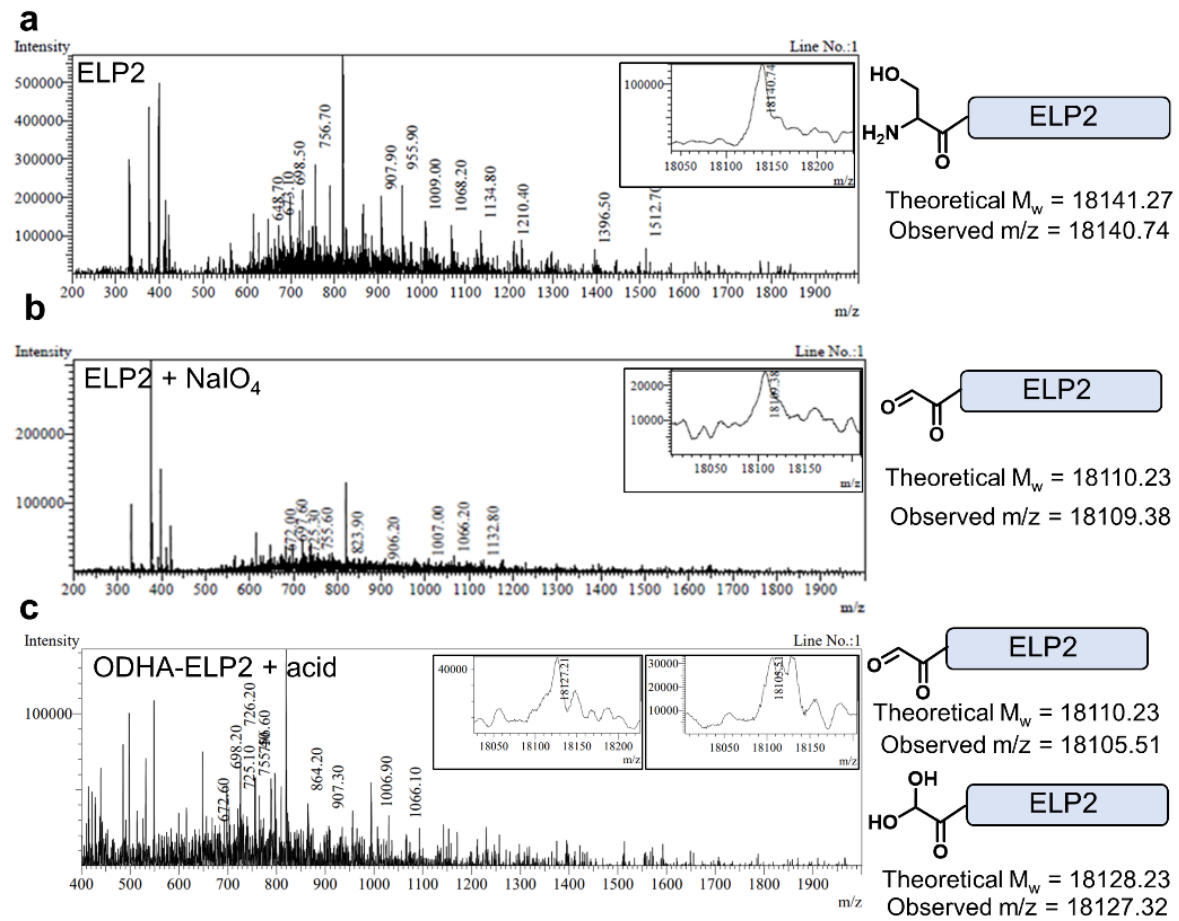

Figure S11. LC-MS analysis confirms the site of the acid-promoted hydrolysis in ODHA-ELP2. Trace spectra, deconvoluted mass, theoretical molecular weight, and observed $\mathrm{m} / \mathrm{z}$ for a) ELP2. b) periodate oxidized ELP2 c) product of ODHA-ELP hydrolysis in an acidic environment. As shown in Figure S11c, the deconvoluted mass-to-charge ratio $(\mathrm{m} / \mathrm{z}$ ) of hydrolysis product closely matches the $\mathrm{m} / \mathrm{z}$ for the periodate oxidized ELP2, supporting the cleavage of oxime bond under acidic $\mathrm{pH}$. We point out that in the acidic buffers, we primarily detect the hydrate (product of water addition to an aldehyde to form geminal diol).
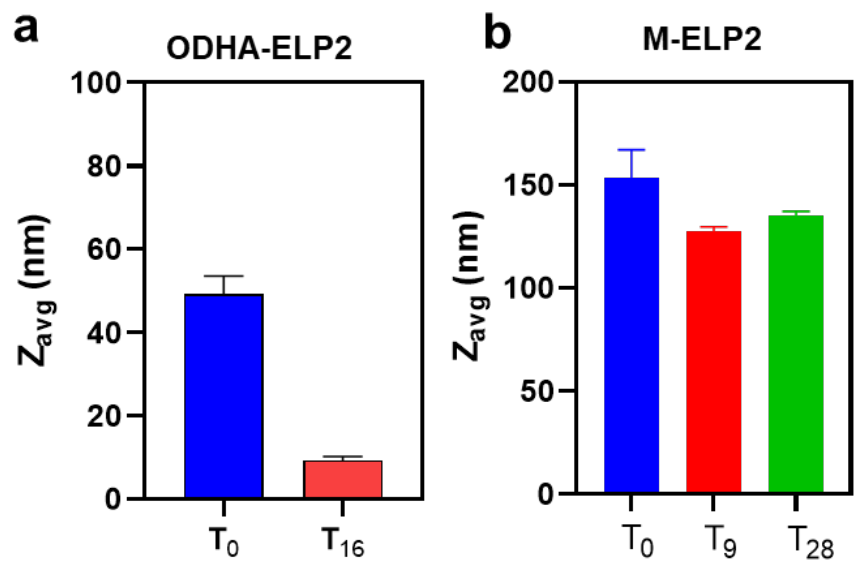

Figure S12. DLS analysis of programmable disassembly of ODHA-ELP2 and comparison with non pHresponsive M-ELP2. a) The average hydrodynamic radius of ODHA-ELP2 decreases upon incubation in an acidic buffer, consistent with the disassembly of protein nanoparticles. b) M-ELP2 particles remain stable after prolonged incubation in the acidic buffer. The subscript denotes the total incubation time in the acidic buffer. Error bars represent the standard deviation of three measurements. 


\section{References}

(1) Tirelli, N.; Amabile, S.; Cellai, C.; Pucci, A.; Regoli, L.; Ruggeri, G.; Ciardelli, F. New Terthiophene Derivatives for Ultrahigh Molecular Weight Polyethylene-Based Absorption Polarizers. Macromolecules 2001, 34 (7), 2129-2137.

(2) McDaniel, J. R.; MacKay, J. A.; Quiroz, F. G.; Chilkoti, A. Recursive Directional Ligation by Plasmid Reconstruction Allows Rapid and Seamless Cloning of Oligomeric Genes. Biomacromolecules 2010, 11 (4), 944-952.

(3) Mozhdehi, D.; Luginbuhl, K. M.; Simon, J. R.; Dzuricky, M.; Berger, R.; Varol, H. S.; Huang, F. C.; Buehne, K. L.; Mayne, N. R.; Weitzhandler, I.; Bonn, M.; Parekh, S. H.; Chilkoti, A. Genetically Encoded LipidPolypeptide Hybrid Biomaterials That Exhibit Temperature-Triggered Hierarchical Self-Assembly. Nat. Chem. 2018, 10 (5), 496-505.

(4) Hossain, M. S.; Liu, X.; Maynard, T. I.; Mozhdehi, D. Genetically Encoded Inverse Bolaamphiphiles. Biomacromolecules 2019, acs.biomac.9b01380.

(5) Luginbuhl, K. M.; Mozhdehi, D.; Dzuricky, M.; Yousefpour, P.; Huang, F. C.; Mayne, N. R.; Buehne, K. L.; Chilkoti, A. Recombinant Synthesis of Hybrid Lipid-Peptide Polymer Fusions That Self-Assemble and Encapsulate Hydrophobic Drugs. Angew. Chemie Int. Ed. 2017, 56 (45), 13979-13984.

(6) Meyer, D. E.; Chilkoti, A. Purification of Recombinant Proteins by Fusion with Thermally-Responsive Polypeptides. Nat. Biotechnol. 1999, 17 (11), 1112-1115.

(7) Wendeler, M.; Grinberg, L.; Wang, X.; Dawson, P. E.; Baca, M. Enhanced Catalysis of Oxime-Based Bioconjugations by Substituted Anilines. Bioconjug. Chem. 2014, 25 (1), 93-101.

(8) Meyer, D. E.; Chilkoti, A. Quantification of the Effects of Chain Length and Concentration on the Thermal Behavior of Elastin-like Polypeptides. Biomacromolecules 2004, 5 (3), 846-851.

(9) Hassouneh, W.; Zhulina, E. B.; Chilkoti, A.; Rubinstein, M. Elastin-like Polypeptide Diblock Copolymers SelfAssemble into Weak Micelles. Macromolecules 2015, 48 (12), 4183-4195.

(10) Simon, J. R.; Carroll, N. J.; Rubinstein, M.; Chilkoti, A.; López, G. P. Programming Molecular Self-Assembly of Intrinsically Disordered Proteins Containing Sequences of Low Complexity. Nat. Chem. 2017, 9 (6), 509515.

(11) Weller, D.; McDaniel, J. R.; Fischer, K.; Chilkoti, A.; Schmidt, M. Cylindrical Polymer Brushes with Elastin-like Polypeptide Side Chains. Macromolecules 2013, 46 (12), 4966-4971.

(12) McDaniel, J. R.; Weitzhandler, I.; Prevost, S.; Vargo, K. B.; Appavou, M. S.; Hammer, D. A.; Gradzielski, M.; Chilkoti, A. Noncanonical Self-Assembly of Highly Asymmetric Genetically Encoded Polypeptide Amphiphiles into Cylindrical Micelles. Nano Lett. 2014, 14 (11), 6590-6598.

(13) Frisken, B. J. Revisiting the Method of Cumulants for the Analysis of Dynamic Light-Scattering Data. Appl. Opt. 2001, 40 (24), 4087.

(14) Jencks, W. P. Studies on the Mechanism of Oxime and Semicarbazone Formation. J. Am. Chem. Soc. 1959, $81(2), 475-481$.

(15) Kalia, J.; Raines, R. T. Hydrolytic Stability of Hydrazones and Oximes. Angew. Chemie Int. Ed. 2008, 47 (39), 7523-7526.

(16) Yildiz, I. A DFT Approach to the Mechanistic Study of Hydrozone Hydrolysis. J. Phys. Chem. A 2016, 120 (20), 3683-3692.

(17) Ulrich, S.; Boturyn, D.; Marra, A.; Renaudet, O.; Dumy, P. Oxime Ligation: A Chemoselective Click-Type Reaction for Accessing Multifunctional Biomolecular Constructs. Chem. - A Eur. J. 2014, 20 (1), 34-41.

(18) Kölmel, D. K.; Kool, E. T. Oximes and Hydrazones in Bioconjugation: Mechanism and Catalysis. Chem. Rev. 2017, 117 (15), 10358-10376. 